\title{
Identificação de Estilos Parentais: O Ponto de Vista dos Pais e dos Filhos
}

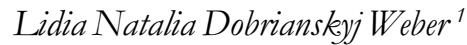 \\ Paulo Müller Prado \\ Ana Paula Viezzer ${ }^{2}$ \\ Olivia Justen Brandenburg ${ }^{2}$ \\ Universidade Federal do Paraná
}

\begin{abstract}
Resumo
A fim de explorar os estilos parentais entre famílias brasileiras, 239 crianças (de 9 a 12 anos, de duas escolas municipais de Curitiba) e seus respectivos pais responderam a duas escalas de responsividade e exigência parental. Estas escalas, que categorizam quatro estilos parentais, foram adaptadas de adolescentes para crianças e apresentaram índices de consistência interna adequados (alpha entre 0,58 e 0,76 ). Os pais foram classificados como: $45,4 \%$ negligentes, $32,8 \%$ autoritativos, $11,8 \%$ permissivos e $10,1 \%$ autoritários. Embora os pais tenham se percebido como mais responsivos e exigentes do que seus filhos perceberam, a correlação entre as respostas dadas pelas crianças e por seus pais foi significativa e positiva. Além disso, a percepção das crianças, de suas mães, foi correlacionada com a percepção delas de seus pais. As diferenças de percepção dos estilos parentais foram discutidas e as pesquisadoras chamam a atenção para o número muito alto de famílias negligentes observado.

Palavras-chave: Estilo parental; práticas educativas parentais; disciplina.
\end{abstract}

\section{Parenting Style: Perceptions of Children and their Parents}

\begin{abstract}
In order to explore parenting styles among Brazilian families, 239 children (9-12 yrs old), from two public schools in Curitiba, and their parents answered two scales of parental responsiveness and demandingness. These scales, which categorize four parenting styles, were adapted for use with children (they were originally developed to be anwered by adolescents) and showed satisfactory reliability coefficients (alpha between 0,65 and 0,76). Parents were classified as: negligent (45,4\%), authoritative (32,8\%), indulgent (11,8\%) and authoritarian $(10,1 \%)$. Although parents have perceived themselves as being more responsive and demanding when compared to the opinions of their children, the correlation between the answers of parents and children was significant and positive. Additionally, the childrens' perceptions of their mothers correlated with that of their fathers. These differences in perception of parenting styles are discussed and the researchers call attention to the high number of negligent families observed.

Keywords: Parenting style; parenting practices; discipline.
\end{abstract}

Desde a década de 1930, cientistas têm se preocupado com questões como "Qual a melhor forma de educar os filhos?" e "Quais são as conseqüências que podem ser provocadas no desenvolvimento das crianças educadas por diferentes modelos de pais?" (Darling \& Steinberg, 1993). O modelo teórico de Baumrind (1960) sobre os tipos de controle parental foi um marco nos estudos que vêm sendo feitos sobre a educação paisfilhos, servindo como base para um novo conceito de estilos parentais que integra aspectos emocionais e comportamentais.

Baumrind (1966) propôs o controle parental autoritativo (authoritative ${ }^{3}$ ) como sendo o mais efetivo que os dois outros tipos de controle: o autoritário e o permissivo. Isso foi comprovado em suas pesquisas (Baumrind, 1967, 1971; Baumrind \& Black,

${ }^{1}$ Endereço para correspondência:UFPR-Departamento de Psicologia-PçSantos Andrade, 50/1º, 80060 000,Curitiba, PR.E-mail: lidiaw@uol.com.br.

Nossa gratidão ao Marco A. P. Teixeira (Universidade Federal do Rio Grande do Sul) que nos forneceu sua ajuda e autorização para adaptação e validação de sua versão traduzida das escalas utilizadas na presente pesquisa.

${ }^{2}$ Apoio: $\mathrm{CNPq}$

${ }^{3}$ Nome de difíiil tradução, sem correspondente em português. Pesquisadores brasileiros mantiveram o nome "autoritativo" (Costa \& cols., 2000), ou adotaram outros nomes para este estilo como democrático-recíproco (Oliveira \& cols., 2002) ou competente (Bee, 1996).
1967) de observação de crianças em idade pré-escolar, com o objetivo de identificar comportamentos dos pais associados a comportamentos competentes dos filhos. Os resultados mostraram que as crianças educadas por diferentes estilos de comportamento dos pais diferiam no grau de competência social. Maior assertividade, maior maturidade, conduta independente e empreendedora, responsabilidade social, todos esses aspectos investigados nas crianças foram associados com o estilo parental chamado por Baumrind de autoritativo.

A partir de suas pesquisas, Baumrind (1966) propôs um modelo de classificação dos pais com três protótipos de controle: autoritativo, autoritário e permissivo. Esta autora definiu os pais autoritativos como sendo aqueles que tentam direcionar as atividades de suas crianças de maneira racional e orientada; incentivam o diálogo, compartilhando com a criança o raciocínio por detrás da forma como eles agem, solicitam suas objeções quando ela se recusa a concordar; exercem firme controle nos pontos de divergência, colocando sua perspectiva de adulto, sem restringir a criança, reconhecendo que esta possui interesses próprios e maneiras particulares; não baseiam suas decisões em consensos ou no desejo da criança. 
Os pais autoritários, segundo Baumrind (1966), modelam, controlam e avaliam o comportamento da criança de acordo com regras de conduta estabelecidas e normalmente absolutas; estimam a obediência como uma virtude e são a favor de medidas punitivas para lidar com aspectos da criança que entram em conflito com o que eles pensam ser certo.

Já os pais permissivos, para Baumrind (1960), tentam se comportar de maneira não-punitiva e receptiva diante dos desejos e ações da criança; apresentam-se para ela como um recurso para realização de seus desejos e não como um modelo, nem como um agente responsável por moldar ou direcionar seu comportamento.

O estilo parental permissivo foi desmembrado em dois, estilo indulgente e estilo negligente, por Maccoby e Martin (1983), quando esses autores reorganizaram os protótipos de Baumrind através de duas dimensões: exigência (demandingness) e responsividade (responsiveness). Desta forma, as características de cada estilo puderam ser sistematizadas através destas duas dimensões: pais autoritários são exigentes e não responsivos, ou seja, as exigências deles estão em desequilibrio com a aceitação das exigências dos filhos, dos quais se espera que inibam seus pedidos e demandas; pais indulgentes são responsivos e não exigentes; pais autoritativos são exigentes e responsivos, ou seja, há uma reciprocidade, os filhos devem responder às exigências dos pais, mas estes também aceitam a responsabilidade de responderem, o quanto possível, aos pontos de vista e razoáveis exigências dos filhos; pais negligentes são não exigentes e nem responsivos, tendem a orientar-se pela esquiva das inconveniências, o que os faz responder a pedidos imediatos da crianças apenas de forma a findá-los (Maccoby \& Martin, 1983).

Assim, a linha de estudo sobre estilos parentais englobou também as famílias negligentes. Porém cabe aqui diferenciar o que é um estilo parental negligente do que é a negligência abusiva, considerada uma violência contra criança na literatura sobre maustratos. A negligência considerada como maltrato ocorre quando os responsáveis de cobrir as necessidades básicas (necessidades físicas, sociais, psicológicas e intelectuais) não as levam a cabo (Roig \& Ochotorena, 1993). Já o estilo parental negligente referese aos pais que não se envolvem com seus papéis de pais e a longo prazo, os componentes do papel parental tendem a diminuir cada vez mais, às vezes a desaparecer, até restar uma mínima relação funcional entre pais e filhos (Maccoby \& Martin, 1983).

Na pesquisa de Dornbusch, Ritter, Leiderman, Roberts e Fraleigh (1987) foram utilizados os três estilos parentais da tipologia de Baumrind (autoritário, autoritativo e permissivo). Estes autores, no entanto, fizeram uma observação importante sobre o fato de o conceito da permissividade incluir dois estilos de pais diferentes (indulgente e negligente). Lamborn, Mounts, Steinberg e Dornbusch (1991) contribuíram nos estudos sobre estilos parentais quando elaboraram escalas que medissem estes dois estilos separadamente.

Lamborn e colaboradores (1991) desenvolveram duas escalas, uma de responsividade e outra de exigência. A escala de responsividade mede o quanto o adolescente percebe seus pais como amorosos, responsivos e envolvidos. A escala de exigência mede o quanto os pais monitoram e supervisionam o adolescente. A combinação das dimensões permite classificar o estilo parental dos pais. Nos resultados foi importante a comprovação de que adolescentes que descrevem seus pais como indulgentes são diferentes dos que descrevem seus pais como negligentes. Estas duas escalas foram traduzidas para o português e validadas no Brasil por Costa, Teixeira e Gomes (2000).

Darling e Steinberg (1993) realizaram uma revisão histórica do conceito de estilo parental, incluindo críticas e mudanças, propondo o entendimento de estilo parental como o contexto em que os pais influenciam seus filhos através de suas práticas de acordo com suas crenças e valores, indo além da combinação entre exigência e responsividade. Ressaltaram a importância de se manter clara a diferença entre "estilo" parental e "práticas" parentais (Darling \& Steinberg, 1993). As práticas parentais correspondem a comportamentos definidos por conteúdos específicos e por objetivos de socialização; diferentes práticas parentais podem ser equivalentes para um mesmo efeito no filho. As práticas são estratégias com o objetivo de suprimir comportamentos considerados inadequados ou de incentivar a ocorrência de comportamentos adequados (Alvarenga, 2001). Os pais podem utilizar-se da combinação de várias destas estratégias, variando de acordo com as situações (Reppold, Pacheco, Bardagi \& Hutz, 2002). Já os estilos parentais constituem o conjunto de atitudes dos pais que cria um clima emocional em que se expressam os comportamentos dos pais, os quais incluem as práticas parentais e outros aspectos da interação pais-fillhos que possuem um objetivo definido, tais como: tom de voz, linguagem corporal, descuido, mudança de humor (Darling \& Steinberg, 1993). Os estilos parentais são "manifestações dos pais em direção a seus filhos que caracterizam a natureza da interação entre esses” (Reppold \& cols., 2002, p. 23).

O conceito de estilo parental foi ampliado desde Baumrind (1966) até Darling e Steinberg (1993). Assim, o estudo sobre práticas disciplinares deixou de restringir-se ao papel de controle, passando a abranger o aspecto de responsividade às necessidades das crianças e, mais ainda, englobando tudo o que contribui para a constituição do clima emocional em que o filho é educado.

O estudo do relacionamento pais-filhos por meio de estilos parentais tem sua relevância por evitar o risco de interpretações erradas a respeito de associações entre aspectos isolados da conduta dos pais e características dos filhos. Comportamentos específicos de pais, como bater, podem trazer conseqüências para o desenvolvimento dos filhos; porém, enfocar qualquer destes comportamentos isoladamente pode levar a uma interpretação errônea (Darling, 1999).

Muitas pesquisas têm descoberto relações entre estilos parentais e diferentes aspectos dos filhos. Em Dornbusch e colaboradores (1987), numa pesquisa envolvendo um grupo experimental numeroso (7836 indivíduos) e diversificado, 
os estilos parentais foram relacionados com a performance escolar dos adolescentes: os estilos autoritário e permissivo foram associados a notas baixas e o autoritativo a notas altas.

Lamborn e colaboradores (1991) realizaram uma pesquisa com uma amostra heterogênea de aproximadamente 4000 indivíduos e tiveram o seguinte resultado: adolescentes que perceberam seus pais como autoritativos mostraram mais aspectos positivos de desenvolvimento (alto índice de competência psicológica e baixo índice de disfunção comportamental e psicológica), enquanto os que perceberam seus pais como negligentes mostraram aspectos negativos; adolescentes que viram seus pais como autoritários ou como indulgentes apresentaram características tanto positivas quanto negativas. Parte dos mesmos adolescentes (2300 indivíduos) que participaram desta pesquisa de Lamborn e colaboradores responderam aos mesmos questionários um ano depois. Observou-se que as diferenças de ajustamento do adolescente conforme o estilo parental de seus pais mantiveram-se ou ainda tiveram um aumento (Steinberg, Lamborn, Darling, Mounts \& Dornbusch, 1994).

Os filhos de pais autoritativos têm sido associados sempre a aspectos positivos como melhor desempenho nos estudos (Steinberg, Darling \& Fletcher, 1995; Cohen \& Rice, 1997), uso de estratégias adaptativas (Aunola, Stattin \& Nurmi, 2000), maior grau de otimismo (Weber, Viezzer \& Brandenburg, 2002). Enfim, filhos de pais autoritativos são vistos como socialmente e instrumentalmente mais competentes do que os filhos de pais não autoritativos (Darling, 1999).

Os filhos de mães autoritárias em geral apresentam comportamento de externalização (agressão verbal ou física, destruição de objetos, mentira) e de internalização (retração social, depressão, ansiedade) (Oliveira \& cols., 2002). Em outros estudos os filhos de pais autoritários foram descritos como tendo tendência para um desempenho escolar moderado, sem problemas de comportamento; porém possuem pouca habilidade social, baixa auto-estima e alto índice de depressão (Cohen \& Rice, 1997; Darling, 1999).

Pesquisas realizadas com apenas os três tipos de estilos (autoritativos, autoritários e permissivos), encontraram que os filhos de pais permissivos tendem a apresentar uso de tabaco e álcool (Cohen \& Rice, 1997), baixa capacidade de auto-regulação (Patock-Peckham, Cheong, Balhorn, Nagoshi, 2001) e baixa habilidade de reação a conflitos (Miller, DiIorio \& Dudley, 2002).

Quando separados os pais permissivos em indulgentes e negligentes, os resultados mais negativos aparecem relacionados com os filhos de pais negligentes, que possuem o menor desempenho em todos os domínios. Possuem baixo rendimento escolar, sintomas depressivos e baixa auto-estima (Darling, 1999; Radziszewska, Richardson, Dent \& Flay, 1996), podem ter um desenvolvimento atrasado, problemas afetivos e comportamentais (Quintin, 2001) e possuem maior índice de estresse (Weber, Biscaia, Pavei \& Galvão, 2002).

Além de os estilos parentais influenciarem em diversos aspectos no desenvolvimento dos filhos, podem estar determinando o estilo parental que os filhos vão adotar futuramente, havendo uma transmissão intergeracional de estilos parentais. Uma pesquisa recente encontrou correlação positiva entre o autoritarismo de avós e mães, ou seja, as filhas educadas por mães autoritárias tenderam a adotar este mesmo estilo parental com seus próprios filhos (Oliveira \& cols., 2002).

A presente pesquisa teve como objetivo dar continuidade a estes estudos, adaptando e validando para crianças as escalas de Exigência e Responsividade de Lamborn e colaboradores (1991), originalmente elaboradas para adolescentes (validadas no Brasil por Costa \& cols., 2000), a fim de investigar o modo como os pais educam seus filhos por meio das categorias de estilos parentais, verificando o nível de concordância entre as crianças e seus pais (pai e mãe), como também a concordância entre as mães e os pais.

\section{Método}

\section{Participantes}

Participaram desta pesquisa 239 crianças da $4^{\text {a }}$ série (de 9 a 12 anos) de duas escolas municipais da região de Curitiba, e seus respectivos pais ou responsáveis. $\mathrm{Na}$ ausência dos pais, as crianças responderam em relação às pessoas que exercem o papel de pais e que possuem maior contato de educação (avós, tios, padrastos, madrastas, entre outros), como procedeu Slicker (1998). A amostra foi de 360 crianças para a análise da validação das escalas. Os dados destas 121 crianças a mais não foram utilizadas nas demais análises pelo fato de seus respectivos pais não terem respondido às escalas, impossibilitando comparações (dentre estas 121 crianças, 75 eram de uma escola particular).

\section{Instrumentos}

Foram utilizadas duas escalas (de responsividade e de exigência) que avaliam estilos parentais. As escalas utilizadas foram validadas no Brasil para adolescentes por Costa e colaboradores (2000) que basearam-se nas usadas por Lamborn e colaboradores(1991). Todas as questões foram avaliadas por meio de um sistema Likert de 3 pontos. Com a autorização de Costa e colaboradores houve adaptações das escalas para esta pesquisa, com mudança da linguagem (expressões regionais) e de situações que eram específicas da fase de adolescência, possibilitando assim a aplicação para crianças. Para viabilizar a aplicação do mesmo instrumento aos pais, a adaptação foi feita na construção das frases, portanto os pais responderam sobre seus próprios comportamentos. 


\section{Procedimento}

Primeiramente foi feito contato com Costa e colaboradores (2000) para a autorização do uso das escalas e devidas adaptações. Foram contatadas duas escolas e com a autorização destas a aplicação foi realizada em grupos contendo no máximo 7 crianças. As escalas direcionadas aos pais foram entregues e devolvidas por intermédio das próprias crianças. Escalas que não possuíam os correspondentes de seus pais ou responsáveis foram excluídas da análise de dados de pais e filhos, exceto na análise da validação da escala.

\section{Análise de dados}

Foram calculados os escores totais de cada escala (os valores foram contados em dobro quando se considerou pais e mães combinados). Assim, para a análise das dimensões de responsividade e de exigência foi utilizada a mediana da amostra para avaliar se os escores foram altos ou baixos, excluindo-se aqueles que obtiveram valor igual à mediana. Foi feita então a classificação dos estilos parentais da seguinte forma: pais com escore alto em ambas dimensões correspondem ao estilo autoritativo; com escore baixo em ambas dimensões, ao estilo negligente; com escore baixo em responsividade e alto em exigência, ao estilo autoritário; com escore alto em responsividade e baixo em exigência, ao estilo indulgente.

Estas escalas sofreram um processo de confirmação de sua estrutura originalmente proposta, através do uso da análise exploratória de componentes principais com avaliação da validade convergente e discriminante de suas dimensões (Hair, Anderson,
Tatham \& Black, 1995), bem como avaliação da consistência interna das variáveis componentes do modelo, de forma a permitir a verificação de sua estrutura inicial.

\section{Resultados e Discussão}

\section{Validação das escalas de exigência e responsividade}

As escalas validadas para adolescentes por Costa e colaboradores (2000) foram analisadas na presente pesquisa através dos índices de consistência interna (alpha de Cronbach) e de uma análise de componentes principais. Isto possibilitou a investigação da validade componencial do instrumento em uma amostra diferenciada, que neste caso é de crianças.

Osíndices de consistência interna (alpha de Cronbach) obtidos na análise da escala de exigência foram (considerando as respostas das crianças): para pais e mães combinados 0,65; para os pais 0,58 ; para as mães 0,61 . E os índices de consistência interna obtidos na análise da escala de responsividade foram: para pais e mães combinados 0,76 ; para os pais 0,71 ; para as mães 0,73 . Os índices de consistência interna encontrados podem ser considerados adequados para uso em pesquisa.

A análise de componentes principais, com rotação varimax, possibilitou uma investigação estrutural dos itens de cada escala. Os resultados desta análise podem ser melhor observados na Tabela 1. Como o objetivo foi desenvolver uma escala que possa ser aplicada tanto para os pais e para as mães, optou-se por realizar a análise com a amostra conjunta de pais e mães.

Tabela 1

Componentes Obtidos através da Análise de Componentes Principais, Considerando os Escores dos Pais Combinados

\begin{tabular}{|c|c|c|c|c|}
\hline \multirow[t]{2}{*}{ Questões das Escalas } & \multicolumn{4}{|c|}{ Componentes } \\
\hline & 1 & 2 & 3 & 4 \\
\hline Responsividade - questão 1 & 0,632 & & & \\
\hline Responsividade - questão 4 & 0,624 & & & \\
\hline Responsividade - questão 7 & 0,601 & & & \\
\hline Responsividade - questão 5 & 0,519 & & & \\
\hline Responsividade - questão 6 & 0,509 & & & \\
\hline Responsividade - questão 2 & 0,506 & & & \\
\hline Responsividade - questão 3 & 0,500 & & & \\
\hline Exigência - questão 6 & & 0,707 & & \\
\hline Exigência - questão 4 & & 0,661 & & \\
\hline Exigência - questão 5 & & 0,611 & & \\
\hline Responsividade - questão 9 & & & 0,699 & \\
\hline Responsividade - questão 10 & & & 0,662 & \\
\hline Responsividade - questão 8 & & & 0,638 & \\
\hline Exigência - questão 3 & & & & 0,757 \\
\hline Exigência - questão 2 & & & & 0,719 \\
\hline Exigência - questão 1 & & & & 0,673 \\
\hline
\end{tabular}


Pode-se perceber que os seis itens da escala de exigência foram divididos em dois componentes (componentes 2 e 4 ), com cargas elevadas em cada um. No componente 2 agruparam-se os itens relativos ao quanto os pais sabem sobre os comportamentos dos filhos e no componente 4 os itens relativos às tentativas dos pais em controlar $\mathrm{o}$ comportamento dos filhos. A divisão da escala de exigência em dois componentes também ocorreu na validação realizada por Costa e colaboradores (2000), e exatamente com os mesmos itens.

Já os dez itens da escala de responsividade, os quais na pesquisa de Costa e colaboradores (2000) agruparam-se em apenas um componente, no presente estudo dividiram-se em dois, e com cargas elevadas em cada um. Ficaram agrupados no componente 3 os itens mais relacionados à interação paisfilhos, como por exemplo, conhecer de fato as pessoas com quem o filho se relaciona, conversar e passar tempo juntos. E os demais itens (componente 1) referem-se mais a atitudes como ajudas e incentivos.

A partir das análises realizadas para validação, pode-se considerar que as duas dimensões (exigência e responsividade) são empiricamente distintas. Embora cada uma delas tenha apresentado um desdobramento em dois componentes, a dimensão de responsividade foi separada da de exigência e os índices de consistência interna de cada dimensão podem ser considerados adequados. Assim, optou-se por manter a estrutura original dos indicadores, para possibilitar a comparação com outros estudos já realizados utilizando as mesmas escalas.

\section{Freqüência dos estilos parentais e sua relação com gênero}

$\mathrm{Na}$ amostra estudada foi encontrada uma proporção similar entre os estilos dos pais e os das mães. A freqüência de cada estilo em pais, mães e os dois combinados pode ser observado na Figura 1.

Pode-se observar na Figura 1 que a maioria dos pais e das mães foram classificados como negligentes. É um

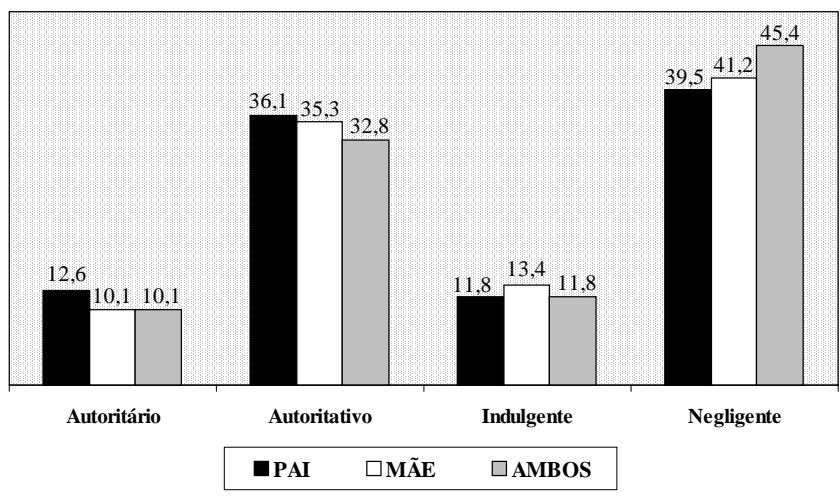

Figura 1. Percentual dos estilos dos pais, das mães e dos dois combinados, considerando apenas os dados obtidos por meio das crianças. percentual muito elevado, considerando que $45,4 \%$ (pai e mãe combinados) engloba quase metade da amostra. Em segundo lugar, $32,8 \%$ dos pais foram classificados como autoritativos. $\mathrm{E}$ os estilos autoritário e indulgente ficaram equilibrados: 10,1\% e $11,8 \%$ respectivamente. Esta proporção foi bastante semelhante à descrita por Lamborn e colaboradores (1991), Steinberg e colaboradores (1994) e Costa e colaboradores (2000).

$\mathrm{Na}$ análise relativa ao gênero, primeiramente foi utilizado o Teste $t$ para amostras independentes para investigar possíveis diferenças entre os gêneros nas dimensões de exigência e responsividade isoladamente. Em um segundo momento, foi utilizado o teste qui-quadrado para investigar possíveis diferenças entre gêneros nas classificações dos estilos parentais (combinação de exigência e responsividade). Estes dois testes aplicados ao gênero foram feitos a partir dos escores combinados de pai e mãe, das escalas respondidas pelas crianças.

Ao analisar os resultados obtidos através do Teste $\underline{t}$, verificou-se uma diferença significativa entre meninos e meninas quanto à exigência $(t=-2,429 ; p=0,016)$. As médias dos escores encontradas nos dois grupos foi de 27,9 para os meninos e 29,7 para as meninas, concluindo-se que, mesmo sendo pequena a diferença entre as médias, os pais (pai e mãe) são um pouco mais exigentes com as filhas do que com os filhos. Já na dimensão de responsividade, não foi possível encontrar diferença significativa entre os gêneros ( $t=-0,982 ; p=0,328$ ), ou seja, os pais (pai e mãe) são tão responsivos com os filhos quanto com as filhas. As médias encontradas foram: 48,7 para meninos e 49,6 para meninas. Esses resultados estão de acordo com aqueles obtidos por Costa e colaboradores (2000).

Ao observar os resultados obtidos através do teste quiquadrado não foi possível verificar diferença significativa entre os gêneros quanto aos quatro estilos previamente classificados $\left(\chi^{2}=4,941 ; \mathrm{gl}=3 ; p=0,170\right)$. Porém, uma análise mais aprofundada pôde mostrar uma sensível diferença entre os sexos. Ao trabalhar apenas com os participantes que classificaram seus pais como autoritativos e negligentes (por serem dois extremos e também por serem os estilos que ocorreram com maior freqüência), então foi possível verificar uma diferença $\left(\chi^{2}=4,878\right.$; gl $=1$; $p=0,027$ ). De todos os meninos (49,5\% da amostra aqui analisada), $70,2 \%$ classificaram seus pais como negligentes e $29,8 \%$ como autoritativos. Ede todas as meninas (50,5\%), 47,9\% classificaram seus pais como negligentes e 52,1\% como autoritativos.

As diferenças encontradas podem ter uma explicação cultural. Normalmente, no senso comum se imagina que as meninas precisam de mais cuidados por serem mais frágeis, e que por sua vez, os meninos são fortes, têm mais autonomia e acabam sendo mais negligenciados por seus pais. $\mathrm{O}$ fato de a diferença encontrada ter sido na dimensão de exigência mostra que os pais controlam mais a filha do que o filho, confirmando a possivel influência de uma cultura machista que dá aos homens uma maior liberdade. 


\section{Comparação entre pais e filho}

Para tornar possível uma comparação entre as respostas dadas pelos filhos e as dos pais seria necessário analisar como os pais se categorizaram com suas próprias respostas, para então comparálas através do teste qui-quadrado. Mas esta análise não foi viável, pois a mediana encontrada na escala de exigência que as mães responderam foi 18 (escore máximo). Isto alterou o processo de classificação, uma vez que todas as mães autoritárias e autoritativas (mães com exigência acima da mediana) seriam eliminadas da amostra. Portanto decidiu-se por fazer uma comparação através da freqüência dos escores obtidos nas escalas dos filhos e seus pais (que pode ser vista nas Tabelas 2 e 3 ) e também através do teste estatístico de correlação.

A partir da Tabela 2 é possível fazer comparações entre as respostas dos filhos e de seus pais. Pode-se perceber que a freqüência do escore total (18) foi bem maior na escala respondida pelos pais e pelas mães do que da escala respondida pelos filhos. Entre as mães, $66,1 \%$ se consideraram totalmente exigentes com seus filhos, e apenas $22,2 \%$ dos filhos as consideraram como tal. 46,4\% dos pais também responderam o escore total, um percentual bem menor que o relativo às respostas das mães $(66,1 \%)$, porém muito maior que o relativo às respostas dos filhos $(5,4 \%)$. Os escores obtidos através das escalas das crianças encontram-se mais distribuídos, enquanto que os escores de mães e pais estão concentrados na maior pontuação.

Pode-se perceber que na dimensão de responsividade não houve grande concentração nos escores mais altos, das escalas respondidas por mães e pais. Mas é possível perceber que mães e pais mostraram uma tendência a apresentar pontuações mais altas que os filhos.

A concentração dos escores de mães e pais, observada nas Tabelas 2 e 3 (principalmente na 2), pode ser explicada de duas formas. Primeiramente, os pais podem sentir-se sugestionados a responderem de maneira socialmente correta. Outra explicação

Tabela 2

Percentual dos Escores Obtidos através da Escala de Exigência Respondida pelos Filhos, Pais e Mães

\begin{tabular}{ccccc}
\hline $\begin{array}{c}\text { Escores de } \\
\text { exigência }\end{array}$ & $\begin{array}{c}\text { Respondido } \\
\text { pela mãe }(\%)\end{array}$ & $\begin{array}{c}\text { Filho respondeu } \\
\text { sobre a mãe }(\%)\end{array}$ & $\begin{array}{l}\text { Respondido pelo } \\
\text { pai }(\%)\end{array}$ & $\begin{array}{c}\text { Filho respondeu } \\
\text { sobre o pai }(\%)\end{array}$ \\
\hline De 6 a 10 & 0,8 & 4,2 & 3,7 & 11,7 \\
11 & 1,3 & 4,2 & 2,5 & 7,5 \\
12 & 1,3 & 7,5 & 4,6 & 11,7 \\
13 & 5,4 & 8,8 & 4,2 & 10,0 \\
14 & 3,3 & 10,5 & 5,4 & 16,7 \\
15 & 4,2 & 13,0 & 9,2 & 13,8 \\
16 & 6,3 & 15,1 & 10,0 & 13,4 \\
17 & 11,3 & 14,6 & 13,8 & 9,6 \\
18 & 66,1 & 22,2 & 46,4 & 5,4 \\
\hline Total & 100,0 & 100,0 & 100,0 & 100,00 \\
\hline
\end{tabular}

Tabela 3

Percentual dos Escores Obtidos através da Escala de Responsividade Respondida pelos Filhos, Pais e Mães

\begin{tabular}{ccccc}
\hline $\begin{array}{c}\text { Escores de } \\
\text { exigência }\end{array}$ & $\begin{array}{c}\text { Respondido } \\
\text { pela mãe }(\%)\end{array}$ & $\begin{array}{c}\text { Filho respondeu } \\
\text { sobre a mãe }(\%)\end{array}$ & $\begin{array}{l}\text { Respondido pelo } \\
\text { pai }(\%)\end{array}$ & $\begin{array}{c}\text { Filho respondeu } \\
\text { sobre o pai }(\%)\end{array}$ \\
\hline De 10 a 20 & 3,3 & 9,9 & 11,2 & 15,9 \\
21 & 1,3 & 3,3 & 2,1 & 9,2 \\
22 & 2,9 & 5,4 & 5,4 & 6,3 \\
23 & 3,3 & 8,4 & 3,8 & 9,6 \\
24 & 5,9 & 9,6 & 7,1 & 10,9 \\
25 & 4,6 & 8,8 & 7,9 & 9,2 \\
26 & 10,9 & 11,3 & 10,5 & 10,0 \\
27 & 18,0 & 11,7 & 16,3 & 13,0 \\
28 & 13,4 & 16,7 & 15,1 & 9,2 \\
29 & 18,8 & 9,6 & 10,5 & 4,6 \\
30 & 17,6 & 5,0 & 10,0 & 2,1 \\
\hline Total & 100,0 & 100,0 & 100,0 & 100,00 \\
\hline
\end{tabular}


é a de que as crianças nem sempre vêem seus pais como eles próprios se vêem, havendo uma certa incompatibilidade, ou seja, os pais agem de um jeito, mas podem ser interpretados de forma diferente pela criança. No caso da escala de exigência, talvez muitos pais e mães considerem ter conhecimento sobre os comportamentos e atividades dos filhos, quando na verdade não o tem.

O teste de correlação foi utilizado para avaliar estatisticamente a concordância entre as respostas dadas pelos filhos e por seus pais. Ao correlacionar a escala de exigência respondida pelo pai com a respondida pelo filho foi encontrado $r=0,240$ $(p<0,001)$; exigência respondida pela mãe com a respondida pelo filho, $r=0,236$ ( $p<0,001)$; responsividade respondida pelo pai com a respondida pelo filho, $r=0,329(p<0,001)$; responsividade respondida pela mãe com a respondida pelo filho, $r=0,268(p<0,001)$. A partir destes dados, constatou-se que a correlação entre as respostas dadas pelas crianças e por seus pais (pai e mãe) foi significativa e positiva, ou seja, pais e filhos apresentaram o mesmo padrão de resposta.

Portanto, pode-se dizer que existe uma relação muito pequena entre as respostas de pais e filhos, pois há uma tendência de pais e mães responderem as pontuações mais altas e os valores de correlação não foram muito altos. Estes valores não tão elevados das correlações pode estar indicando a interferência de outras variáveis na relação entre pais e filhos.

\section{Comparação estatística entre mães e pais}

Para tornar possível a comparação entre mães e pais foram utilizados dois testes: a correlação e o qui-quadrado. Estes testes permitiram avaliar estatisticamente a concordância entre mães e pais. Ao correlacionar a escala de exigência que a criança respondeu sobre seu pai com a que ela respondeu sobre sua mãe foi encontrado $r=0,569(\phi<0,001)$; e na escala de responsividade do pai com a da mãe, $r=0,593(p<0,001)$. A partir destes dados, constatou-se que a correlação entre as respostas dadas pelas crianças sobre suas mães e sobre seus pais foi significativa e positiva, apesar de não ter sido muito elevada. Isso indica que as respostas atribuídas às mães e aos pais apresentaram um mesmo padrão.

O teste qui-quadrado também apresentou semelhança entre os padrões de comportamento de mães e pais. Esta análise foi feita a partir dos estilos categorizados através das escalas respondidas pelos filhos. Os resultados obtidos mostraram que de todas as mães autoritárias, 53,8\% correspondem a pais também autoritários; das mães autoritativas, $75,0 \%$ correspondem a pais autoritativos; das mães indulgentes, $42,1 \%$ correspondem a pais indulgentes; e das mães negligentes, $64,3 \%$ correspondem a pais também negligentes $\left(\chi^{2}=88,553\right.$; gl $\left.=9 ; p<0,001\right)$.

O teste de correlação foi feito também para comparar as dimensões de exigência e responsividade entre as escalas respondidas pelas mães e pelos pais. Ao correlacionar a escala de exigência respondida pelo pai com a respondida pela mãe foi encontrado $r=0,478(\phi<0,001)$; responsividade respondida pelo pai com a respondida pela mãe, $r=0,500(p<0,001)$. Constatou-se então que a correlação entre as respostas dadas pelas mães e pelos pais foi significativa e positiva, ou seja, as respostas das mães e dos pais também apresentaram um mesmo padrão. É interessante observar que os valores de correlação entre mãe e pai (tanto das escalas respondidas pelas crianças quanto das escalas respondidas por mães e pais) foram mais altos que os valores obtidos na comparação entre filhos e pais. A partir destes dados, pode-se dizer que a maior parte das crianças consegue detectar um padrão de práticas parentais relativamente consistente na dupla parental. Entretanto as percepções quanto à intensidade com que os pais exercem controle e dispensam afeto na relação são diferentes para pais e filhos.

A concordância entre as respostas de mães e pais pode trazer uma certa desvantagem para algumas crianças. Se os pais são autoritativos, a princípio não existiriam problemas, mas no caso do estilo negligente (e também do autoritário e permissivo) não há possibilidades de compensação para a criança, que acaba sendo criada num ambiente familiar no qual pai e mãe seguem um mesmo padrão de comportamento.

\section{Conclusão}

O estudo sobre estilos parentais é de grande relevância, uma vez que envolve a familia e conseqüentemente toda a sociedade. Todas as pessoas receberam uma educação que, com certeza, foi muito importante para que elas sejam do jeito que são. A maneira mais adequada de educar e se relacionar com os filhos vem sendo muito pesquisada nas últimas décadas. E o estudo dos estilos parentais trata esse assunto de forma objetiva, investigando o conjunto de comportamentos dos pais que cria um clima emocional em que se expressam as interações paisfilhos, tendo como base a influência dos pais em aspectos comportamentais, emocionais e intelectuais dos filhos.

Ainda se sabe pouco sobre o porquê de os pais adotarem um ou outro estilo parental (Darling \& Steinberg, 1993). Mas já se conhece bastante sobre o que engloba cada um deles e quais são os seus efeitos. Diversas pesquisas desenvolvidas nesta área demonstram que o estilo autoritativo sempre se mostrou como aquele que produz melhores efeitos na formação dos filhos como: melhor desempenho escolar (Cohen \& Rice,1997; Dornbusch \& cols., 1987; Steinberg \& cols., 1995), alto índice de competência psicológica e baixo índice de disfunção comportamental e psicológica (Lamborn \& cols., 1991).

Adotar um estilo parental autoritativo é bastante adequado para uma educação saudável dos filhos. Para adotar este estilo é preciso que os pais se envolvam na educação, respondendo às necessidades que a criança tem de atenção, incentivo, auxílio, diálogo e diversão (responsividade), bem como 
supervisionar e monitorar os comportamentos do filho, exigindo a obediência de regras e limites e o cumprimento de deveres (exigência). Ao mesmo tempo em que os pais precisam ser respeitados em seus papéis, também devem respeitar os direitos dos filhos. Portanto, de um lado há uma posição de controle e de outro uma posição de compreensão e bi-direcionalidade, que oferece à criança maior autonomia e auto-afirmação.

Um aspecto de grande importância está no fato de não só saber o que fazer para educar bem, como também saber se o que está sendo feito é interpretado pela criança como se espera. Pode ocorrer no relacionamento pais-filhos uma certa incompatibilidade de percepções e pensamentos, ou seja, a visão que o filho tem sobre os comportamentos dos pais é diferente da visão que os pais têm deles próprios.

Por mais que se tenha constatado, na presente pesquisa, concordâncias nas respostas dadas por filhos e pais, é possível verificar uma tendência de os pais perceberem a si mesmos como mais responsivos e mais exigentes do que os filhos os percebem. Isso demonstra que os pais percebem sua própria maneira de educar de um jeito e os filhos podem não percebê-la assim (Paulson \& Sputa, 1996). Esta possível incompatibilidade pode ser decorrente de um problema de comunicação, o qual pode consistir no fato de os pais não conseguirem falar a mesma "língua" que a criança e acreditarem que esta é capaz de compreender as atitudes tomadas pelos pais como se fosse um adulto.

Pôde-se verificar na presente pesquisa que a maioria dos pais está agindo de forma considerada inadequada com seus filhos (45,4\% de pais negligentes, $10,1 \%$ de autoritários e $11,8 \%$ de indulgentes, totalizando $67,3 \%$ de pais não autoritativos). É provável, também, que alguns pais sintam-se perdidos em relação ao que devem fazer na educação de seus filhos (não sabem como agir em determinadas circunstâncias), enquanto outros acreditam estar agindo certo por terem sido educados da mesma forma.

Uma intervenção feita com pais é a possibilidade de uma aplicação direta do conhecimento de estilos parentais. Isto significa um processo de munir os pais com conhecimentos específicos e habilidades que lhes permitam promover o desenvolvimento e a competência de suas crianças. Um trabalho de orientação para pais é de extrema importância, pois implica o melhor desenvolvimento de crianças, que por sua vez serão os pais de amanhã, atingindo inclusive outras gerações. A intervenção com pais, como o treinamento, por exemplo, pode acarretar em grande benefício para as familias: melhoria nas atividades parentais e aumento da coesão familiar (Reppold \& cols., 2002). A sociedade como um todo seria beneficiada, já que mais pessoas teriam possibilidades de crescer e se desenvolver em um ambiente familiar saudável. Os pais atuais precisam ter acesso ao conhecimento de práticas educativas que sejam eficazes para criar e manter um repertório de comportamentos adequados, desenvolver habilidades sociais e manter uma dinâmica familiar com muito afeto positivo e comprometimento.

\section{Referências}

Alvarenga, P. (2001). Práticas educativas parentais como forma de prevenção de problemas de comportamento. Em H. J. Guilhardi (Org.), Sobre comportamento e cognição (Vol. 8, pp. 52-57). Santo André, SP: ESETec.

Aunola, K., Stattin, H. \& Nurmi, J. -E. (2000). Parenting styles and adolescents' achievement strategies. Journal of Adolescence, 23, 205-222.

Baumrind, D. (1966). Effects of authoritative control on child behavior. Child Development, 37, 887-907.

Baumrind, D. (1967). Child care practices anteceding three patterns of preschool behavior. Genetic Psychology Monographs, 75, 43-88.

Baumrind, D. (1971). Current patterns of parental authority. Developmental Psychology Monoghraph, 4, 1-103.

Baumrind, D. \& Black, A. (1967). Socialization practices associated with dimensions of competence in preschool boys and girls. Child Development, 38, 291-327.

Bee, H. (1996). A criança em desenvolvimento. Porto Alegre: Artmed.

Cohen, D. A. \& Rice, J. (1997). Parenting styles, adolescent substance use, and academic achievement. Journal of Drug Education, 27, 199-211.

Costa, F. T., Teixeira, M. A. P. \& Gomes, W. B. (2000). Responsividade e exigência: Duas escalas para avaliar estilos parentais. Psicologia: Reflexão e Crítica, 13, 465473.

Darling, N. (1999). Parenting style and its correlates. Parenting style and its correlates. ERIC/EECE Publications - Digests. Retirado em 12/02/2002, do ERIC/ EECE no World Wide Web http://ericeece.org/pubs/digests.html

Darling, N. \& Steinberg, L. (1993). Parenting style as context: An integrative model. Psychological Bulletin, 113, 487-496.

Dornbusch, S. M., Ritter, P. L., Leiderman, P. H., Roberts, D. F. \& Fraleigh, M. J. (1987). The relation of parenting style to adolescent school performance. Child Development, 58, 1244-1257.

Hair, J. F., Anderson, R. E., Tatham, R. L. L. \& Black, W. C. (1995). Multivariate data analysis. New York: Prentice Hall.

Lamborn, S. D., Mounts, N. S., Steinberg, L. \& Dornbusch, S. M. (1991). Patterns of competence and adjustment among adolescents from authoritative, authoritarian, indulgent, and neglectful families. Child Development, 62, 10491065.

Maccoby, E. \& Martin, J. (1983). Socialization in the context of the family: Parentchild interaction. Em E.M. Hetherington (Org.), Handbook of cbild psychology, v. 4. Socialization, personality, and social development (4a ed., pp. 1-101). New York: Wiley.

Miller J. M., DiIorio C. \& Dudley, W. (2002) Parenting style and adolescent's reaction to conflict: Is there a relationship? Journal of Adolescent Health, 31, 463-468.

Oliveira, E. A, Marin, A. H., Pires, F. B., Frizzo, G. B., Ravanello, T. \& Rossato, C. (2002). Estilos parentais autoritário e democrático-recíproco intergeracionais, conflito conjugal e comportamentos de externalização e internalização. Psicologia Reflexão e Crítica, 15, 1-11.

Paulson, S. E. \& Sputa, C. L. (1996). Patterns of parenting during adolescence: Perceptions of adolescents and parents. Adolescence, 31, 369-381.

Patock-Peckham, J. A., Cheong, J., Balhorn, M. E. \& Nagoshi, C. T. (2001). A social learning perspective: A model of parenting styles, self-regulation, perceived drinking control, and alcohol use and problems. Alcoholism: Clinical and Experimental Research, 25, 1284-1292.

Quintin, P. E. (2001). Chamgements familiaux à long terme à la suite d'une intervention écosystémique. Em J. Torrente (Org), La maltraitance - Regars pluridisciplinaires (pp. 191-214). Revigny-sur-Ornain: Hommes et Perspectives.

Radziszewska, B., Richardson, J. L., Dent, C. W. \& Flay, B. R. (1996). Parenting style and adolescent depressive symptoms, smoking, and academic achievement: Ethnic, gender, and SES differences. Journal of Behavior Medicine, 19, 289-305.

Reppold, C. T., Pacheco, J., Bardagi, M. \& Hutz, C. S. (2002). Prevenção de problemas de comportamento e desenvolvimento de competências psicossociais em crianças e adolescentes: Uma análise das práticas educativas e dos estilos parentais. Em C. S. Hutz (Org.), Situações de risco e vulnerabilidade na infância e adolescência: Aspectos teóricos e estratégias de intervenção (pp. 9-51). São Paulo: Casa do Psicólogo. 
Roig, A. M. \& Ochotorena, J. P. (1993). Maltrato y abandono em la infancia. Barcelona: Mariínez Roca.

Slicker, E. K. (1998). Relationship of parenting style to behavioral adjustment in graduating high school seniors. Journal of Youth and Adolescence, 27, 345-372.

Steinberg, L., Darling, N. \& Fletcher, A. C. (1995). Authoritative parenting and adolescent adjustment: An ecological journey. Em P. Moen, G. H. Elder, Jr. \& $\mathrm{K}$. Luscher (Orgs.), Examining lives in context: Perspectives on the ecology of buman development (pp. 423-466). Washington, DC: APA.

Steinberg, L., Lamborn, S. D., Darling, N., Mounts, N. S. \& Dornbusch, S. M. (1994). Over-time changes in adjustment and competence among adolescents from authoritative, authoritarian, indulgent, and neglectful families. Child Development, 65, 754-770.

Weber L. N. D., Viezzer A. P. \& Brandenburg O. J. (2002). A relação entre o estilo parental e o otimismo da criança [Resumo]. Em Sociedade Brasileira de Psicologia (Org.), Resumos de Comunicação Científica, XXXII Reunião Anual de Psicologia (p. 267). Florianópolis, SC: SBP.
Weber, L. N. D., Biscaia, P., Paivei, C. A. \& Galvão, A. (2002). A relação entre o estilo parental e o stress infantil. [Resumo]. Em Conselho Regional de Psicologia do Paraná (Org.), Psicologia em Conexão-40 anos de Profissão, X Encontro Paranaense de Psicologia, Curitiba - PR: CRP - 08.

Sobre os autores

Lidia Natalia Dobrianskyj Weber é Professora do Departamento de Psicologia e do Programa de Pós-graduação em Educação da Universidade Federal do Paraná. É Mestre e Doutora em Psicologia Experimental pela Universidade de São Paulo.

Paulo Müller Prado é Professor do Departamento de Administração Geral e Aplicada. Mestre em. Administração pela Universidade Federal do Paraná. É Doutor em Administração e Marketing pela Escola de Administração de Empresas de São Paulo da Fundação Getúlio Vargas.

Ana Paula Viezzer é Acadêmica do Curso de Psicologia da Universidade Federal do Paraná. É bolsista de Iniciação Científica do CNPq.

Olivia Justen Brandenburg é Acadêmica do Curso de Psicologia da Universidade Federal do Paraná. É bolsista de Iniciação Científica do CNPq. 